\title{
Comparing the Resynthesis of Brassica napus L. by Interspecific Somatic and Sexual Hybridization. II. Hybrid Morphology and Identifying Organelle Genomes
}

\author{
Richard H. Ozminkowski, Jr., ${ }^{1}$ and Pablo Jourdan ${ }^{2}$ \\ Department of Horticulture, The Ohio State University, 2001 Fyffe Court, Columbus OH 43210-1096
}

\begin{abstract}
Additional index words. disomic polyploids, heterozygosity, polyploidy, protoplasts, chloroplast DNA, mitochondrial DNA
Abstract. Brassica napus (genome aacc), a natural allotetraploid derived from hybridization between B. oleracea L. (genome $c c$ ) and $B$. rapa L. (genome $a a$ ), was resynthesized by somatic and sexual hybridization. Seventy-two interspecific somatic $\left(R_{0}\right)$ hybrids and 27 sexual $\left(F_{1}\right)$ hybrids were produced from the same parent plants. $R_{0}$ and $F_{1}$ hybrids displayed morphology that was intermediate to the species parents, but $B$. rapa characteristics tended to predominate. $R_{0}$ hybrids with nuclear DNA content equivalent to natural B. napus were uniform for nuclear-encoded traits, whereas allotetraploid $F_{1}$ hybrids were variable for traits such as morphology, flower color, and seed production. Chloroplast restriction fragment length polymorphisms (RFLPs) showed unequal segregation in the $\mathbf{R}_{0}$ population favoring the chloroplasts of $B$. rapa; two of the $58 R_{0}$ hybrids tested had only the $B$. oleracea marker and 10 contained markers of both parents. Mitochondrial RFLPs showed a similar bias among the $56 \mathrm{R}_{0}$ hybrids tested; only four plants showed $B$. oleracea markers exclusively, and the remaining plants were evenly distributed between having only $B$. rapa markers or having combinations from both species. In contrast, sexual hybrids displayed only maternal organelle markers.
\end{abstract}

The success of a newly synthesized allopolyploid (e.g., triticale $\mathrm{x}$ Triticosecale 'Hakuran', an artificial Brassica napus), is based in part on the heterozygosity of the individuals and the method used for hybridization (Dewey, 1980; Ozminkowski and Jourdan, 1993b). Two means to accomplish such hybridizations are sexual crosses from diploid or tetraploid parents involving reduced (1n) or unreduced $(2 n)$ gametes and protoplast fusion ( $2 n$ somatic cells). While sexual hybridization is often the conventional choice for interspecific combinations, somatic hybridization offers two phenomena, rarely observed in sexual hybrids, that may be of value in germplasm enhancement programs, namely, novel cytoplasmic combinations and retention of intragenomic heterozygosity from the parent plants. The importance of heterozygosity in polysomic polyploids has been extensively discussed (Peloquin and Ortiz, 1992; Sanford, 1983), but its significance in disomic polyploids has not been thoroughly examined. The availability of protoplast fusion and plant regeneration protocols for Brassica spp. provides an opportunity to examine potential advantages of each hybridization method for use in B. napus germplasm enhancement programs.

In the production of interspecific hybrids by sexual crosses, gametes are subject to allelic segregation and gametic competition before embryogenesis that can potentially limit the allelic combinations represented in the $\mathrm{F}_{1}$ hybrid population. The $\mathrm{F}_{1}$ generation per se displays the variability of the parents, and $\mathrm{F}_{1}$ hybrids from heterozygous parents would be nonuniform. However, in cases in which reduced gametes from $2 x$ parents are involved, the $F_{1}$

Received for publication 7 Jan. 1993. Accepted for publication 29 Sept. 1993. Salaries and research support provided by state and federal funds appropriated to the Ohio Agricultural Research and Development Center, The Ohio State Univ. Manuscript no. 55-93. Use of trade names does not imply endorsement of the products named nor criticism of similar ones omitted. We thank K. Song, Univ. of Wisconsin, and C. Makaroff, Miami Univ., for the kind gift of plasmids. The cost of publishing this paper was defrayed in part by the payment of page charges. Under postal regulations, this paper therefore must be hereby marked advertisement solely to indicate this fact.

'Present address: Heinz U.S.A., 13737 Middleton Pike, Bowling Green, OH 43402-9481.

${ }^{2}$ To whom reprint requests should be addressed. generation must be doubled to restore fertility, fixing intragenomic homozygosity. Thus, many independent sexual hybrids may be necessary to incorporate several alleles of interest; yet producing such hybrids can be difficult (Hadley and Openshaw, 1980). Heterozygosity is greatly increased in sexual crosses involving unreduced $(2 n)$ gametes from $2 x$ parents (Peloquin and Ortiz, 1992) and is maximized within a population of allotetraploid somatic hybrids (Sanford, 1983). Each somatic hybrid from a given fusion should be uniform, regardless of the initial heterozygosity of the parent lines; in practice, somatic hybrid populations are extremely variable in morphology, often due to aneuploidy or chromosomal aberrations (Austin et al., 1986; Bravo and Evans, 1985; Sundberg et al., 1987). However, a single somatic hybrid containing a balanced genome from each parent can, in theory, encompass all of the nuclear genome variability available in the parents, since it contains all alleles from each parent plant; this occurs because the diploid cells used for fusion are not subject to allelic segregation. Thus, in contrast to sexual hybrids, extensive variation in subsequent generations would be expected and could be used to enhance germplasm. Given these various factors, we seek to determine whether more significant variability is obtained within a population of sexual interspecific hybrids and their progeny or within progeny of a single somatic hybrid.

There have been few studies assessing the significance of somatic and sexual hybridization. While biological differences between the two methods have been discussed (Glimelius, 1985; Negrutiu et al., 1989), the few comparisons made between hybrids from each method have been limited to the Solanaceae (Evans et al., 1982; Power et al., 1978; Sabour et al., 1986); these studies reported much greater variability among somatic than sexual hybrids. Since different tissues were used as sources of protoplasts from each parent (e.g., callus and leaf), artifacts, such as cultureinduced variation, or variation within seed lots, not represented in both populations have confounded the evaluation. We have reported the production of sexual and somatic hybrids between $B$. oleracea (genome $c c$ ) and $B$. rapa (genome $a a$ ) to synthesize $B$. napus (genome aacc) (Ozminkowski and Jourdan, 1993b). Here we report on some morphological characteristics of these populations and describe the organelle composition of the plants. 


\section{Materials and Methods}

Plant material. Open-pollinated cultivars of the two progenitor species were used to produce highly heterozygous intraspecific species parents (Ozminkowski and Jourdan, 1993b). A single $B$. oleracea species parent plant (-2) and two siblings of the $B$. rapa species parent ( -3 and -4$)$ were propagated by in vitro shoot culture and individual clones used as parents in somatic and sexual interspecific hybridizations. Seventy-two somatic $\left(\mathrm{R}_{0}\right)$ hybrids were produced from two independent protoplast fusion experiments, each experiment differing in the $B$. rapa sibling used as the source of protoplasts. Twenty-seven allodiploid sexual $\left(\mathrm{F}_{1}\right)$ hybrids were produced through embryo rescue from crosses between B. olerace -2 and B. rapa-3. Chromosome doubling by colchicine treatment was successful in eight $\mathrm{F}_{1}$ hybrids. All plants were grown in a greenhouse and evaluated for morphology and seed production after selfing or crossing with B. napus 'Westar' (Ozminkowski and Jourdan, 1993a).

Organelle DNA characterization. Total DNA was isolated from greenhouse-grown plants (Doyle and Dickson, 1987). Genomic DNA of $58 \mathrm{R}_{0}, 27 \mathrm{~F}_{1}$ hybrids, and species parents was digested with various restriction enzymes as recommended by the manufacturers (Boehringer, Indianapolis; BRL, Gaithersburg, Md.), run on $0.8 \%$ agarose gels, and transferred to nylon membranes (Zetabind, Cuno, Meriden, Conn.). Chloroplast DNA (cpDNA) was characterized on EcoRI blots with a cpDNA-specific probe under high stringency conditions (Song et al., 1990). The probe $\mathrm{p} 8 \mathrm{a}$ is a $3.8 \mathrm{~kb}$ PstI-SalI fragment from orchid cpDNA that hybridizes to a $6.5 \mathrm{~kb}$ cpDNA fragment in $B$. oleracea and to a 4.3 kb cp DNA fragment in B. rapa after restriction with EcoRI (Song and Osborn, 1992). Mitochondrial DNA (mtDNA) was characterized on the same plants (except for two somatic hybrids) using four restriction enzyme-probe combinations that differentiated the species parents (Bam HI/s10.1, EcoRI/s10.1, BglI/p5.2, and EcoRI/ p5.2); probes were mtDNA fragments isolated from B. rapa and corresponded to the restriction map reported by Palmer and Shields (1984).

\section{Results}

Morphology and growth habit of species parents. The species parents used in somatic and sexual interspecific hybridization were derived from intraspecific (intersubspecific) crosses of diverse morphotypes of each species. The resulting plants combined characteristics derived from the four cultivars involved in their generation (Table 1). Some simple characteristics (e.g., pigmentation of flowers or anthers) were inherited in a dominant-recessive fashion, whereas more complex ones (e.g., response to vernaliza- tion, leaf shape, or hypocotyl swelling) tended to be intermediate to the parental cultivars. Siblings of a cross were generally very uniform in growth habit. We did not detect any significant novel characteristics (i.e., not present in either parent) in these hybrids. Although the cultivars used for intraspecific hybridization were open-pollinated, reciprocal crosses were made only between selected pairs of individuals to minimize variability among siblings.

Brassica oleracea hybrids derived from subspecies crosses have been described as unspecialized mongrels (Lester, 1989), and the hybrids we obtained fit that description. The more salient features of the B. oleracea parent were caulescent habit and white petals from cauliflower and purple veins and anther tips from kale. White flower color is conferred by a single dominant allele in $B$. oleracea (Dickson and Wallace, 1986). The plants had thick leaves with a waxy surface, which gave them an opaque, blue-green appearance. The plants were not vernalized initially and required nearly 6 months to flower in the greenhouse. A cold treatment at $4 \mathrm{C}$ for 4 weeks reduced the time to flower and also resulted in more prolific flowering. The plants did not form heads like cauliflower, but racemes were more clustered than in the kale parent and produced normal flower buds that opened quickly. The flowers produced abundant, highly viable pollen; they were self-compatible and set abundant seed (Ozminkowski and Jourdan, 1993a).

The B. rapa parent plants had neither of the pronounced characteristics of the two cultivar parents, i.e., rounded hypocotyl and heading foliage. The two individuals ( -3 and -4$)$ used in hybridization were uniform and rosette in habit, having only slightly swollen plant bases. The presence of a swollen hypocotyl in turnip is believed to be controlled by a major gene, but the extent of swelling is determined by multiple genes (McGrath and Quiros, 1991). The leaves of these plants were thinner and lighter green than those of $B$. oleracea, but were covered throughout with trichomes. The $B$. rapa hybrids responded to vernalization, as did the $B$. olerace a hybrids, by earlier and much more prolific flowering. Significant differences in growth habit were noted between vernalized and nonvernalized plants mainly attributable to a longer vegetative phase in the latter (not shown). Both siblings produced yellow flowers that shed abundant, viable pollen and both plants were self-incompatible but could be crossed with each other (Ozminkowski and Jourdan, 1993a).

Morphology of somatic $\left(R_{0}\right)$ hybrids. All $\mathrm{R}_{0}$ hybrids were pubescent while in vitro and as they matured and displayed a growth habit generally intermediate to the species parents (Fig. 1 A and B). Thirty-one hybrids derived from two fusion experiments were homogeneous and were classified as type-1 hybrids based on morphology and DNA content (Ozminkowski and Jourdan, 1993b). These hybrids were nearly rosette in form (Fig. 1A); they grew vigorously and displayed characteristics more similar to the $B$.

Table 1. Morphological characteristics of cultivar parents ${ }^{\mathrm{z}}$, species parents, and interspecific hybrids between the species parents.

\begin{tabular}{|c|c|c|c|c|c|c|c|c|}
\hline \multirow[b]{2}{*}{ Trait } & \multicolumn{4}{|c|}{ Open-pollinated cultivars } & \multicolumn{2}{|c|}{ Species parent } & \multicolumn{2}{|c|}{ Hybrids } \\
\hline & Cauliflower & Kale & Turnip & $\begin{array}{l}\text { Chinese } \\
\text { cabbage }\end{array}$ & $\begin{array}{l}\text { Brassica } \\
\text { oleracea }\end{array}$ & $\begin{array}{c}\text { Brassica } \\
\text { rapa }\end{array}$ & Somatic & Sexual \\
\hline Plant base & Normal & Normal & Swollen & Normal & Normal & Swollen & Normal & Normal \\
\hline Habit & Caulescent & Near rosette & Rosette & Heading & Caulescent & Near rosette & Near rosette & Variable \\
\hline Node color & Light green & Purple & Purple & Light green & Purple & Green & Purple & Green to purple \\
\hline Leaf shape & Spatulate & Petiolate & Divided & Spatulate & Petiolate & Divided & Divided & Variable \\
\hline Foliage color & Blue-green & Blue-green & Light green & Green & Blue-purple & Green & Blue-green & Variable \\
\hline Vein color & Light green & Purple & Light green & Light green & Purple & Light green & Light green & Variable \\
\hline Vesture & Glabrous & Glabrous & Pubescent & Pubescent & Glabrous & Pubescent & Pubescent & Pubescent \\
\hline Inflorescence & Heading & Loose & Loose & Loose & Small heads & Loose & Loose & Loose \\
\hline
\end{tabular}

${ }^{\mathrm{z}}$ Characteristics in bold are those for which parents were selected. 


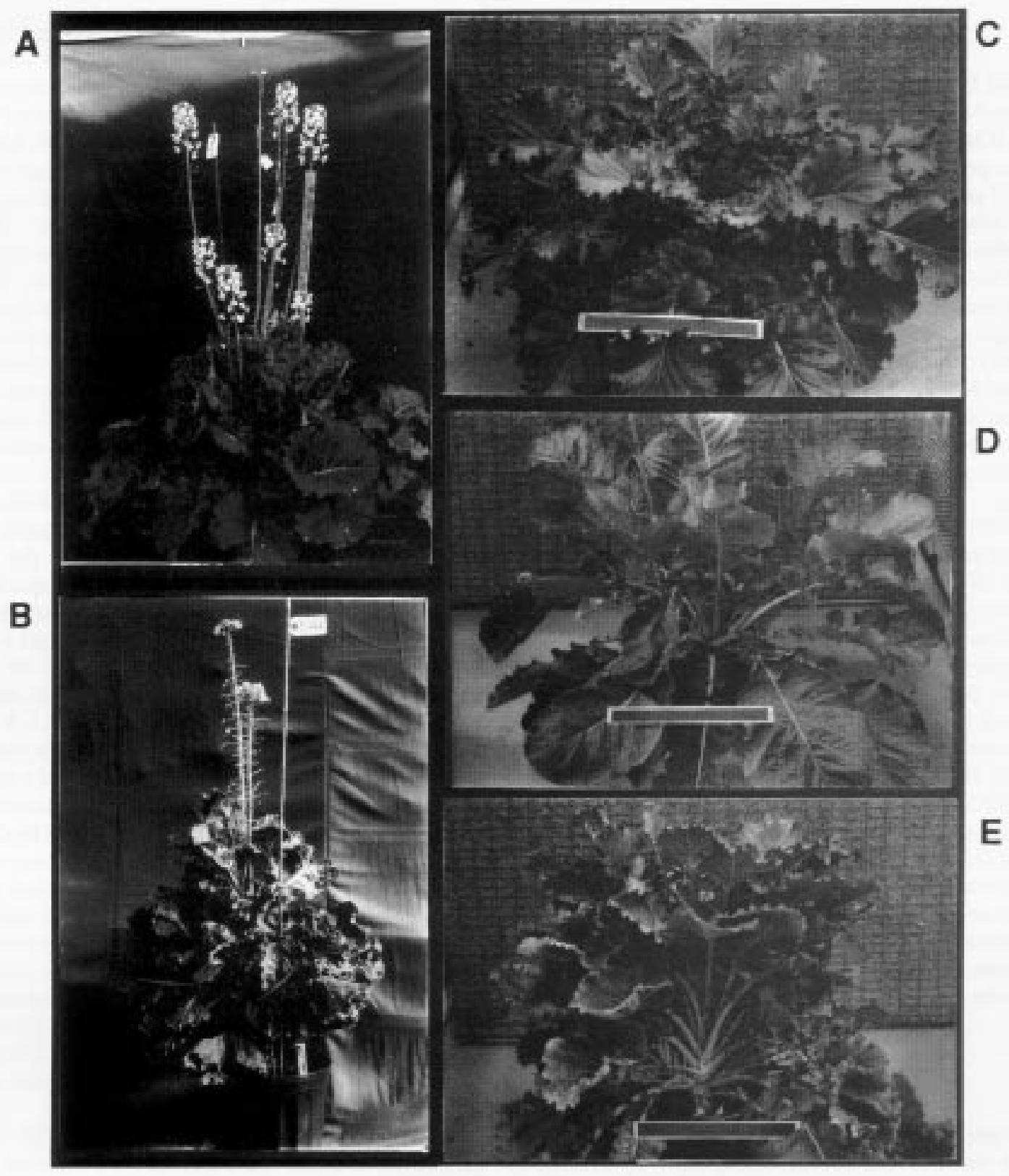

Fig. 1. Growth habit of somatic and sexual hybrids. (A) Type-1 $\mathrm{R}_{0}$ hybrid. (B) Type-2 $\mathrm{R}_{0}$ hybrid. $(\mathbf{C}-\mathbf{E}) \mathrm{F}_{1}$ hybrids; marker $=30 \mathrm{~cm}$.

rapa parent, particularly in overall habit and leaf shape (Fig. 2A). Young plants of this type had trichomes over the entire leaf surface, but mature plants had trichomes mainly along the margins or midribs of leaves. The leaves were a dark, intense green. The 27 remaining plants, type- 2 hybrids, were caulescent but more variable in form (Fig. 1B); mature foliage of most plants was nearly glabrous and always more rugose than type- 1 plants, ranging from slight to extreme (Fig. 2A). Most of these plants had a more $B$. oleracea-like appearance and their DNA content approached hexaploid or higher (Ozminkowski and Jourdan, 1993b), a result suggesting that they had two $B$. oleracea genomes and one $B$. rapa genome (aaccc genome constitution).

Racemes of some $\mathrm{R}_{0}$ hybrids grew to a height of almost $3 \mathrm{~m}$ and initially had few branches. The first type-1 hybrid flowered $\approx 7$ months after fusion (3 months in soil) without vernalization; most other type- 1 hybrids flowered soon after. Accurate times to flower were difficult to establish at first because hybrids were transferred from in vitro conditions at different times. When shoot cuttings were propagated in the greenhouse under uniform conditions, the plants flowered at about the same time. Petals were pale yellow as flowers opened, turning white soon after anthesis; the petals eventually folded back forming a slight cone-shaped flower (Fig. 3B). All but one of the 31 type- 1 plants had white flowers; the one unique plant had uniformly pale yellow flowers that were intermediate to the yellow and white flowers of the cultivar parents (Table 2).

In contrast to the normal, uniform flowering of type- 1 hybrids, most type- 2 plants were delayed in flowering by up to as much as 6 months. The racemes were often malformed, producing buds that occasionally opened into flowers having asymmetrical petals, although most aborted. Plants with opened flowers were usually chimeric for color (yellow or white), often within individual flowers. The size of flowers and petals was variable within this group, but flowers were $\approx 25 \%$ larger than those of type- 1 plants.

Morphology of the sexual $\left(F_{1}\right)$ hybrids. Preliminary characterization of $F_{1}$ hybrids was done before colchicine treatment, but, in general, chromosome doubling mainly increased plant size and did not affect overall vigor. In cases in which colchicine treatment 


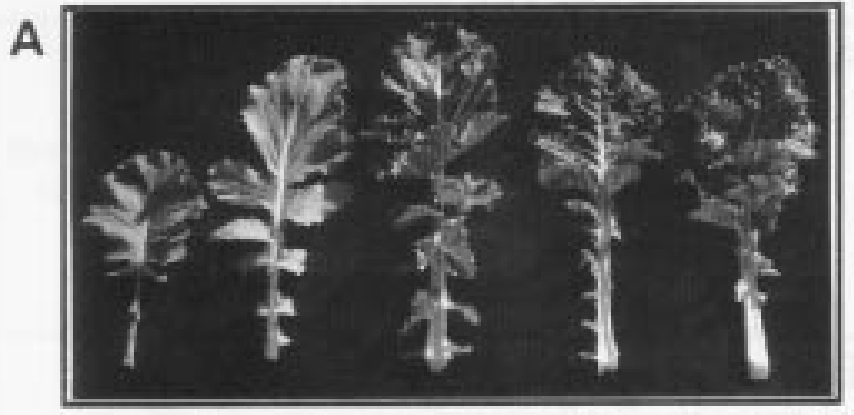

B

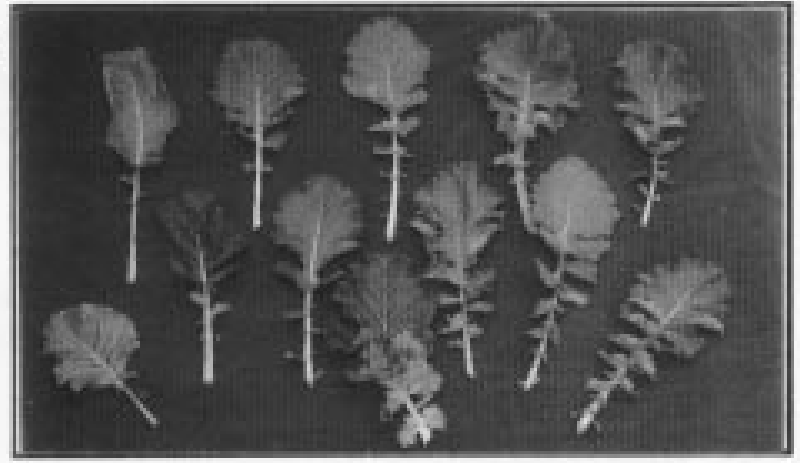

Fig. 2. Leaf morphology of parents and hybrids. (A) $\mathrm{R}_{0}$ hybrids. Left to right: Brassica oleracea species parent, $B$. rapa species parent, type- $1 \mathrm{R}_{0}$ hybrid, and two type-2 $\mathrm{R}_{0}$ hybrids. (B) $\mathrm{F}_{1}$ hybrids. Brassica oleracea parent in lower left, type- $1 \mathrm{R}_{0}$ hybrid in lower right.

resulted in higher ploidy than allotetraploids, the plants were noticeably abnormal and highly rugose, resembling somewhat the type- $2 \mathrm{R}_{0}$ hybrids. As within the $\mathrm{R}_{0}$ population, all $\mathrm{F}_{1}$ hybrids were pubescent while in vitro; however there was significant variation in leaf shape among them. Once in soil, differences within this population became more pronounced (Fig. 1 C-E, Fig. 2B). All plants were vigorous and remained pubescent. Trichome density and location varied, but they were always present on the margins and upper surface. No two plants were identical, and none of the sexual hybrids closely resembled the $\mathrm{R}_{0}$ hybrids. Most differences in morphology, such as leaf margin ruffling, leaf coloration, plant habit, extent of hypocotyl swelling, stem color, and leaf shape, were continuous and difficult to quantify (Fig. 2B). Thus, $F_{1}$ plants could not be readily grouped by morphology, as was done in the $\mathrm{R}_{0}$ population.

The first $F_{1}$ hybrid flowered after 5 months in soil, 10 months after pollination of the species parents. Vernalization of large $F_{1}$ hybrids (4 to 6 months in soil) reduced the time to flower for most plants by at least 1 month, although one plant flowered earlier than its vernalized clone. Most nonvernalized plants eventually flowered within 9 months after placement in soil. One $\mathrm{F}_{1}$ hybrid did not bolt after nearly 1 year in soil, whereas its vernalized clone flowered, a result implying an obligate chilling requirement. Another hybrid did not flower, even after 5 weeks of exposure to $4 \mathrm{C}$; apparently this plant required an even longer chilling treatment. Petal color segregated among the $\mathrm{F}_{1}$ hybrids (Table 2 ) in a 1 white : 1 yellow ratio $\left(P=0.01, \chi^{2}\right.$ test $)$.

Fertility and seed production. We have described the fertility of somatic hybrids (Ozminkowski and Jourdan, 1993a) and here concentrate on the comparison of $\mathrm{R}_{0}$ and $\mathrm{F}_{1}$ hybrids produced with B. rapa-3. In general, all type- $1 \mathrm{R}_{0}$ hybrids had similar levels of male and female fertility, whereas the allotetraploid $F_{1}$ hybrids differed markedly in their female fertility. Pollen viability was generally similar in both groups of plants.

In uncontrolled pollinations in our greenhouse, $B$. napus

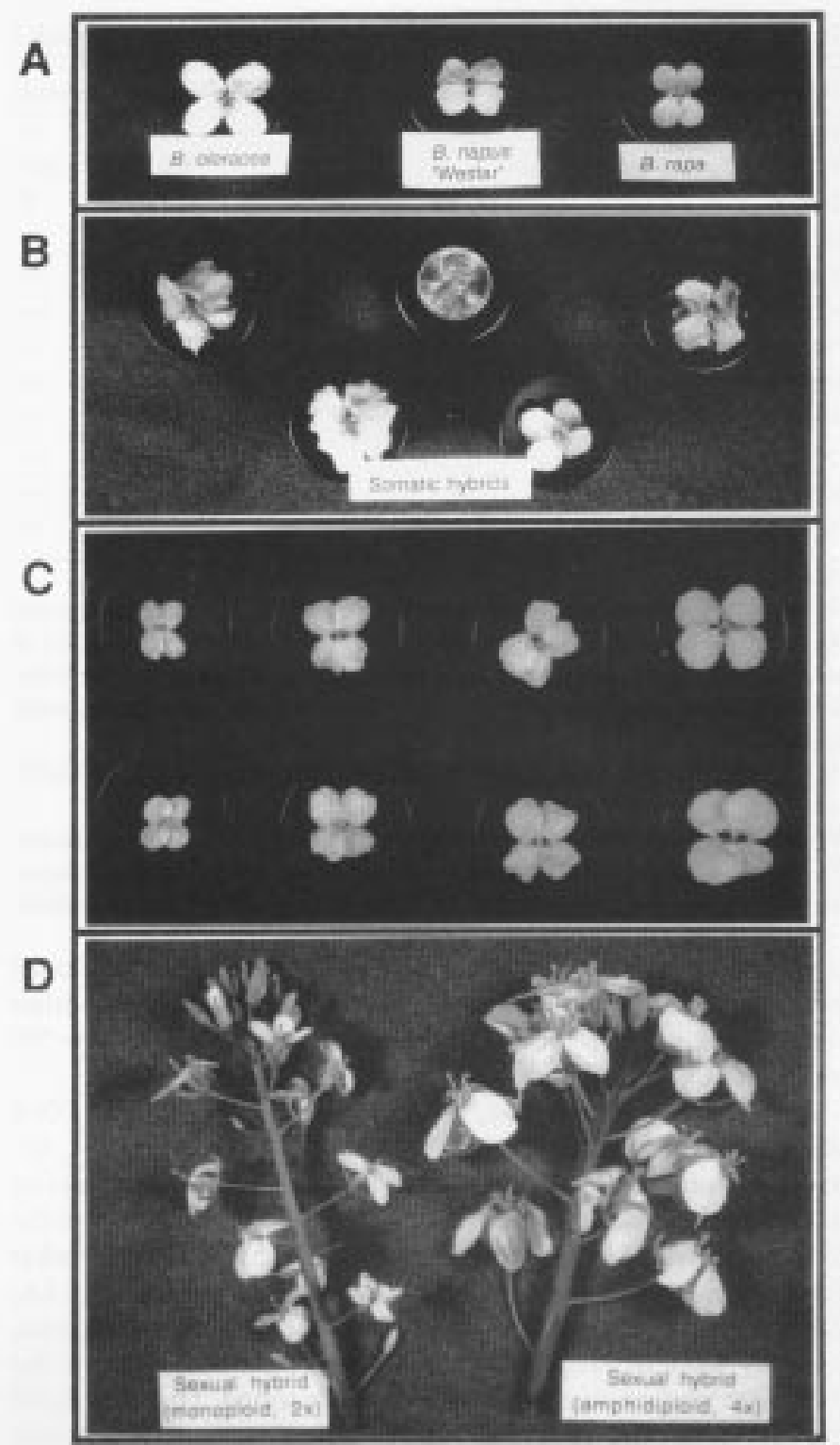

Fig. 3. Floral characteristics of (A) species parents and Brassica napus 'Westar', (B) $\mathrm{R}_{0}$ hybrids (the two flowers at left and the one on upper right corner are from type-2 plants while the lower right is from a type-1 plant), $(\mathbf{C})$ allodiploid $\mathrm{F}$ hybrids, (D) inflorescence in $\mathrm{F}_{1}$ hybrid \#18 before (left) and after colchicine treatment (right). The coin marker is $19 \mathrm{~mm}$ in diameter.

'Westar', a highly self-fertile spring rapeseed cultivar, produced an average of $18 \pm 8$ seeds per silique. Under similar conditions, the $\mathrm{R}_{0}$ hybrids produced $11 \pm 3$ seeds per silique ( $\approx 61 \%$ of 'Westar'), and the $\mathrm{F}_{1}$ hybrids produced less than one seed per silique. Increased seed production in the eight $\mathrm{F}_{1}$ hybrids required repeated pollinations, so the values we obtained (avg. $6 \pm 5$ seeds per silique, $33 \%$ of 'Westar') represent a probable maximum capacity for seed set in these plants (Table 2). The percentage fruit set also varied among the $\mathrm{F}_{1}$ hybrids, from $40 \%$ in one case to $100 \%$ in another. Microscopic examination of pistils for pollen germination and penetration of the stigma showed that none of the sexual hybrids had a typical sporophytic self-incompatibility response. However, the amount of pollen that remained on a stigma after fixation (i.e., had germinated) was generally lower than that for the somatic hybrids (Ozminkowski and Jourdan, 1993a). Although the $\mathrm{R}_{0}$ hybrids all set abundant seed when crossed with 'Westar', the $\mathrm{F}_{1}$ hybrids varied in proportion to the ability 
Table 2. Summary of some characteristics in somatic and sexual hybrids. ${ }^{2}$

\begin{tabular}{lcccr}
\hline \hline Characteristic $^{\mathrm{y}}$ & \multicolumn{2}{c}{ Somatic hybrids } & \multicolumn{2}{c}{ Sexual hybrids } \\
\hline Brassica rapa parent $_{\text {No. of fusions or pollinations }}$ & -3 & -4 & -3 & -4 \\
${\text { Total } \mathrm{R}_{0} \text { or } \mathrm{F}_{1} \text { hybrids }^{\mathrm{x}}}^{\mathrm{w}}$ & 49 & 1 & 510 & 241 \\
Allotetraploid hybrids $^{\mathrm{w}}$ & 20 & 11 & 27 & 0 \\
Petal color & All W & $10 \mathrm{~W}: 1 \mathrm{C}$ & $13 \mathrm{~W}: 11 \mathrm{Y}$ & ---- \\
Anther tip color & All P & All P & $16 \mathrm{P}: 8 \mathrm{Y}$ & --- \\
Pistil color & All P & All P & $17 \mathrm{P}: 7 \mathrm{G}$ & --- \\
Pollen viability & $92 \pm 2$ & $95 \pm 4$ & $88 \pm 4$ & --- \\
Compatibility & SC & SI & SC & --- \\
Seed set (self) & $11 \pm 3^{\mathrm{v}}$ & --- & $6 \pm 5(3-10)^{\mathrm{u}}$ & --- \\
Seed set (cross) & $20 \pm 4$ & --- & $10 \pm 9(2-23)$ & --- \\
Cytoplasm (cp and $\mathrm{mt})$ & Variable & Variable & Maternal & ---
\end{tabular}

${ }^{\mathrm{z} A l l}$ hybridizations were done with $B$. oleracea -2 .

${ }^{\mathrm{y}} \mathrm{W}=$ white $\mathrm{C}=$ cream, pale-yellow; $\mathrm{Y}=$ yellow; $\mathrm{P}=$ purple $; \mathrm{G}=$ green; $\mathrm{SC}=$ self-compatible; $\mathrm{SI}=$ self-incompatible. Evaluations of color in petal, anther tip, and pistil were done at the allodiploid level in $\mathrm{F}_{1}$ hybrids. Includes allodiploid (amphihaploid) sexual hybrids and higher-ploidy hybrids.

${ }^{\text {w} H y b r i d s ~ w i t h ~ b a l a n c e d ~ g e n o m e s ~ a n d ~} 38$ chromosomes $(\approx 2.4$ pg DNA/2C nucleus).

${ }^{\mathrm{v}}$ Spontaneous seed set in the greenhouse, expressed as seeds per silique. "Based on repeated pollinations and expressed as seeds per silique. Numbers in parenthesis indicate the range in seed set per sexual hybrid.

to set selfed seed; plants with few selfed seed also produced few seeds from crosses either with 'Westar' or with other sexual hybrids. $\mathrm{F}_{1}$ hybrid \#18 produced 10 seeds/pod $(\mathrm{n}=50)$ and \#8 as low as one seed per pod.

cpDNA characterization. Examining cpDNA in total DNA extracts revealed a biased chloroplast sorting-out among $\mathrm{R}_{0}$ hybrids, whereas the $27 \mathrm{~F}_{1}$ hybrids displayed only the chloroplast marker of the maternal parent (Fig. 4A, Table 3). Only two of the $58 \mathrm{R}_{0}$ plants tested exhibited the $B$. olerace $a .5 \mathrm{~kb}$ cpDNA marker alone; 46 plants exhibited only the B. rapa $4.3 \mathrm{~kb}$ marker (Fig. 4A; Table 3). The 10 remaining hybrids showed both parental markers, i.e., they were heteroplastidic; one was a type- 1 hybrid and the other nine were among the 27 type- 2 plants tested. To determine if the heteroplastidic state was stable during vegetative development, a second DNA isolation and analysis of four hybrids was done $\approx 6$ weeks later, and the results confirmed the original patterns. In four cases, individual type- 2 plants derived from the same callus displayed different cpDNA markers (i.e., the B. rapa or both markers). The presence of both cpDNA markers in one plant was more frequent in type- 2 plants ( 9 of 23) than in type- 1 plants ( 1 of 21).

The cpDNA was also examined in $\mathrm{R}_{1}$ progeny from three heteroplastidic hybrids. All 12 progeny of the type- 1 heteroplastidic plant displayed only the $B$. oleracea marker, while 11 progeny of one type-2 heteroplastidic plant displayed only the B. rapa marker. In contrast, the 13 progeny of the other type- 2 hybrid tested varied, with six plants each displaying either the $B$. oleracea or the $B$. rapa marker and one displaying both.

$m t D N A$ characterization. Although only $7 \%$ of the mtDNA genome ( 15.3 of $219 \mathrm{~kb}$ ) has been surveyed so far, a few generalizations about the mtDNA transmission in these hybrids are possible; these are based on analysis of 44 hybrids (21 type- 1 and 23 type- 2 derived from both fusion experiments) and $27 \mathrm{~F}_{1}$ hybrids. Only maternal mitochondrial patterns were observed among the $F_{1}$ hybrids (Fig. 4B, Table 3). The mtDNA transmission patterns in $\mathrm{R}_{0}$ hybrids from both experiments are similar (Table 3), so the data can be combined. A bias was found in mtDNA restriction fragment

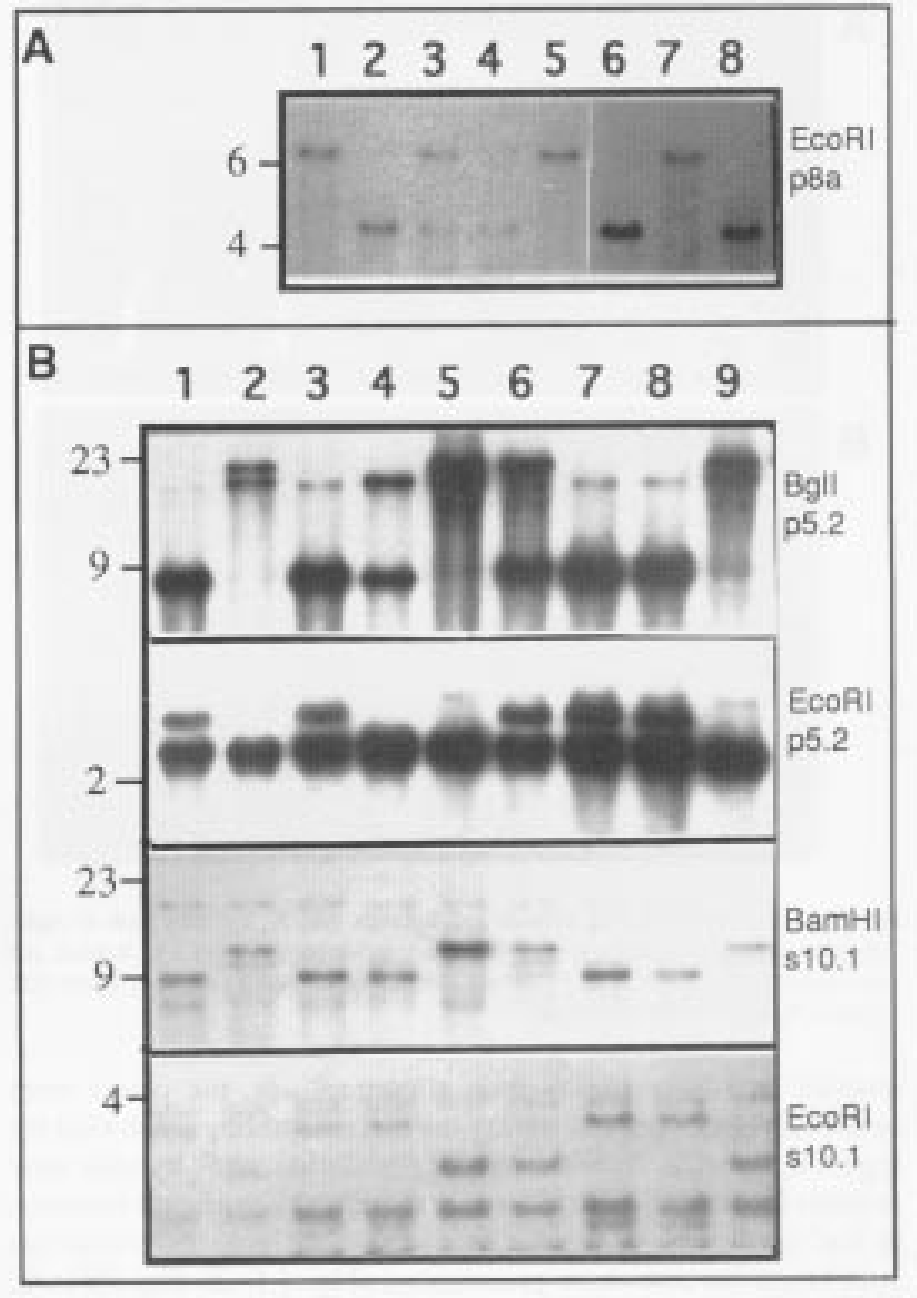

Fig. 4. Organelle restriction fragment length polymorphism markers. (A) Total DNA digested with EcoRI and hybridized with cpDNA-specific probe $\mathrm{p} 8 \mathrm{a}$; lane 1, Brassica oleracea; lane 2, B. rapa; lanes 3-5, type-1 $\mathrm{R}_{0}$ hybrids; lane 6, type- $2 \mathrm{R}_{0}$ hybrid; lane $7, \mathrm{~F}_{1}$ hybrid with $B$. oleracea as pistillate parent; lane 8 , $\mathrm{F}_{1}$ hybrid with $B$. rapa as pistillate parent. (B) Total DNA digested with the restriction enzymes indicated at left (Bgl I, EcoRI, and BamHI) and hybridized with the mtDNA-specific probe specified (p5.2, s10.1). Lanes 1-5 as in A; lane 6 , another type- $1 \mathrm{R}_{0}$ hybrid; lane 7 , a type- $2 \mathrm{R}_{0}$ hybrid; lane $8, \mathrm{~F}_{1}$ hybrid with B. olerace $a$ as pistillate parent; lane $9, \mathrm{~F}_{1}$ hybrid with $B$. rapa as pistillate parent. Numbers at left indicate molecular weights in $\mathrm{kb}$.

length polymorphism (RFLP) sorting-out among $\mathrm{R}_{0}$ hybrids favoring the $B$. rapa patterns. Only two hybrids displayed exclusively $B$. oleracea markers in all four mtDNA probe-enzyme combinations, and both were type- 2 plants. About one-half of the somatic hybrids ( 11 of 21 type- 1 and 9 of 23 type- 2 ) showed only $B$. rapa patterns, and the remainder (10 of 21 type- 1 and 12 of 23 type-2) contained a mixture of parental bands. No novel bands were noted in this limited survey. For example, in the type- 1 hybrids represented by lanes 4 and 6 (Fig. 4B), EcoRI digests show B. oleracea patterns with one probe and B. rapa patterns for the other. Multiple shoots regenerated from five calluses exhibited different mitochondrial constitution, a result indicating that sorting-out occurred either late in the callus or early in the shoot development stages.

\section{Discussion}

The observations we have gathered on 58 somatic hybrids and 27 sexual hybrids produced between the same $B$. oleracea and $B$. rapa parent plants permit us to assess the outcomes of the two 
Table 3. Distribution of mtDNA restriction fragment length polymorphism (RFLP) patterns among somatic and sexual hybrids categorized in relation to the cpDNA.

\begin{tabular}{|c|c|c|c|c|c|c|c|c|c|c|}
\hline \multirow[b]{3}{*}{ Plant type } & \multicolumn{3}{|c|}{ Brassica oleracea $\mathrm{cp}$} & \multicolumn{3}{|c|}{ Brassica rapa $\mathrm{cp}$} & \multicolumn{3}{|c|}{ Mixture $^{z} \mathrm{cp}$} & \multirow[b]{3}{*}{ Total } \\
\hline & \multicolumn{9}{|c|}{ Mitochondrial type ${ }^{y}$} & \\
\hline & ole & rap & mix & ole & rap & mix & ole & rap & $\operatorname{mix}$ & \\
\hline \multicolumn{11}{|c|}{ Somatic hybrids } \\
\hline \multicolumn{11}{|l|}{ Fusion 1 (with B. rapa-4) } \\
\hline Type-1 & --- & --- & --- & --- & $5^{\mathrm{x}}$ & 3 & --- & --- & 1 & 9 \\
\hline Type-2 & --- & --- & --- & --- & 4 & 2 & --- & 1 & 2 & 9 \\
\hline \multicolumn{11}{|l|}{ Fusion 2 (with B. rapa-3) } \\
\hline Type-1 & --- & 1 & --- & --- & 5 & 6 & --- & --- & --- & 12 \\
\hline Type- 2 & --- & 1 & --- & 2 & 2 & 4 & --- & 1 & 4 & 14 \\
\hline Total based on cpDNA ${ }^{w}$ & & 2 & & & 33 & & & 9 & & 44 \\
\hline \multicolumn{11}{|c|}{ Sexual hybrids } \\
\hline$c c \times \mathrm{aa}^{\mathrm{v}}$ & 19 & --- & --- & --- & --- & --- & --- & --- & --- & 19 \\
\hline$a a \times c c$ & --- & --- & --- & --- & 8 & --- & --- & --- & --- & 8 \\
\hline
\end{tabular}

${ }^{\mathrm{z}}$ These plants contained cpDNA RFLP markers of both parents.

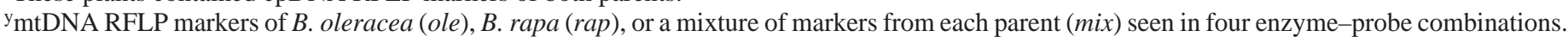

${ }^{\mathrm{x}}$ Numbers of hybrids with the combination.

wTotal number of somatic hybrids grouped by their cpDNA composition

${ }^{\mathrm{V}}$ Indicates the direction of the cross; $a a=B$. rapa-3, $c c=$ B. oleracea-2.

hybridization methods. We have confirmed previous findings that hybrids derived from protoplast fusion are not uniform, since they differ in ploidy levels, morphology, fertility, and cytoplasmic composition. Some of this variability can be attributed to biological and technical aspects of protoplast fusion. First, the fusion process is uncontrolled and multiple fusion events are common; however, survival of such multiple fusion products will likely be limited to a pair or two of cells. Fusions involving more than four cells are unlikely to be viable. Second, the development of fusion products into microcolonies and calluses followed by shoot regeneration is commonly accompanied by uncontrolled (and generally undesirable) variation. Such somaclonal variation associated with simple mutations, chromosomal aberrations, nuclear genetic instabilities, and mitotic recombination (Bravo and Evans, 1985) may be minimized by reducing the period of time fusion products exist as unorganized cell clusters and inducing plant regeneration as quickly as possible. Third, mixing organelles from two cells in a heterokaryon is also accompanied by poorly understood - and so far uncontrolled - processes such as intergenomic recombination in chloroplasts (rare occurrence) (Medgyesy et al., 1985) and mitochondria (common occurrence) (Newton, 1988). The outcomes of such myriad events among the population of organelles in a fusion product are not entirely predictable. In addition, the influence of cytoplasmic genomes on major plant characteristics such as morphology has not been conclusively demonstrated, yet they may be important in certain cases. For example, dramatic differences in growth habit and leaf shape have been observed in reciprocal crosses between subspecies of $B$. rapa, a result suggesting that cytoplasmic components (or maternal effects) play a role in specific genotype combinations within Brassica (McGrath and Quiros, 1991).

Notwithstanding the opportunity for such broad-based variability, we established that, within each fusion experiment, plants having balanced chromosome numbers (type-1, $n=19$ chromosomes, $2 \mathrm{C}$ DNA $=2.4 \mathrm{pg}$ ) displayed remarkable uniformity in morphology and fertility although they exhibited some variability in organelle composition. These 31 type- 1 plants support the expectation that somatic hybrids from highly heterozygous par- ents would be uniform and would contain all the allele combinations present in the parents. The type- 1 hybrids derived from each fusion experiment could be considered clones for nuclear-encoded characteristics. However, the use of morphological markers limits the confidence with which one can assume the clonal nature of these plants. We observed one pale yellow flowered variant among the 31 type- 1 hybrids, a result suggesting that other, perhaps less obvious, variations may be present in these plants. Extensive characterization of the hybrids for markers such as RFLPs would be much more informative.

The variability for factors potentially critical to a germplasm enhancement program (morphology, ploidy, fertility) that we observed in $\mathrm{R}_{0}$ plants can be attributed to the fusion and culture process; such variant plants represent less useful material and can be discarded to concentrate on further work with the type-1 hybrids. Only one of these hybrids may be needed to generate $\mathrm{R}_{1}$ progeny to analyze segregating characteristics. We would expect that segregation in the $\mathrm{R}_{1}$ progeny of each somatic hybrid would be similar, if not identical. The fact that all $\mathrm{R}_{0}$ hybrids in the two experiments arose from only two combinations of three parent plants supports such expectations. However, empirical evaluation of such progeny is needed.

In keeping with the effects of in vitro culture, considerable variation has been commonly observed in somatic hybrid populations of Brassica (Schenck and Röbbelen, 1982; Sundberg et al., 1987; Terada et al., 1987) and other genera (Bravo and Evans, 1985); however, populations often have been too small to assess the method fairly. A contributing factor to the variation found in previous studies may be the fusion of different cell types (e.g., hypocotyl, leaf, callus, suspensions) to allow visual observation and selection of heterokaryons (Sundberg and Glimelius, 1986). These cell populations may differ in distribution of cell cycle stages and in division rates that may lead to the loss of chromosomes from the more slowly dividing cell when fused (Bravo and Evans, 1985). Another contributing factor may be the use of heterogenous populations of plants as a source of protoplasts. Etiolated hypocotyls frequently have been used in somatic hybridization of Brassica spp.; a typical isolation may use 200 to 500 
seedlings. When we evaluated field populations of the $B$. rapa cultivars and the species parent line, each displayed considerable variability in leaf shape and plant habit (unpublished observations). Thus, had we used protoplasts from hypocotyls for fusion or different plants in somatic and sexual hybridizations, we could have introduced substantial artifactual variability between and within hybrid populations. We avoided these problems by restricting the material used for hybridization to similar cell types and the same plants; thus, we produced a high frequency (53\%) of uniform hybrids. Sundberg et al. (1987) and Jourdan et al. (1989) also found some uniformity in morphology among the few allotetraploid ( $2 n$ $=38$ ) hybrids produced.

In contrast to the uniformity in morphology, isozyme banding patterns, ploidy, and fertility and diversity among organellarparticularly mitochondrial-genomes of $\mathrm{R}_{0}$ hybrids, $\mathrm{F}_{1}$ hybrids were diverse in morphology, isozymes, ploidy, and fertility, yet uniform in organellar composition-depending on the maternal parent. The $\mathrm{F}_{1}$ hybrids were also quite vigorous, even when monoploid, a result indicating congruity between the two species' genomes; this congruity probably occurs because of the common origin of the two species. Although significant chromosome pairing was observed in the monoploids (Ozminkowski and Jourdan, 1993b), it was insufficient for fertility, and doubling was required for seed production. The wide variation in seed set but its consistently lower capacity than 'Westar' or the $\mathrm{R}_{0}$ hybrids demonstrates the problems caused by meiotic irregularities in newly synthetic $B$. napus and the unique characteristic of each $\mathrm{F}_{1}$ hybrid. As a group, the eight allotetraploid $F_{1}$ hybrids were half as fertile as the $R_{0}$ hybrids, but two of them were nearly as fertile. Morphological and physiological variability among the allodiploid and allotetraploid $\mathrm{F}_{1}$ hybrids was extensive: plants differed in growth habit, leaf shape, response to vernalization, flower color, and seed production. The segregation for some traits followed expected disomic inheritance (e.g., flower color), but other traits were quantitative (leaf ruffling).

Previous somatic hybridization studies have indicated an unbiased chloroplast transmission in synthetic $B$. napus and extensive mtDNA recombination-rearrangement (Sundberg and Glimelius, 1991; Temple et al., 1992). Our results concur only with the prevalence of altered mtDNA, because we found strong bias for the B. rapa cp genome. A similar strong bias for the $B$. rapa $\mathrm{cpDNA}$ has been observed in similar fusion experiments (D. Heather, personal communication). Organelle composition in the $\mathrm{F}_{1}$ hybrids completely depended on the maternal parent, as anticipated. Thus, $\mathrm{F}_{1}$ hybrid plants that contained only $B$. oleracea chloroplasts and mitochondria were produced; no $\mathrm{R}_{0}$ hybrids with a similar cytoplasm were obtained. Only one $\mathrm{R}_{0}$ type- 1 hybrid, which was initially heteroplastidic, sorted-out in favor of B. olerace $a$ cpDNA in the $\mathrm{R}_{1}$. Sundberg and Glimelius (1991) found equal chloroplast segregation among $\mathrm{R}_{0}$ hybrids between these same species, but a biased segregation in $\mathrm{R}_{0}$ hybrids between other Brassica spp. of unequal ploidy levels favoring the chloroplasts of the parent with the higher ploidy. Genetic or technical factors must account for the organellar bias we observed. Since there is very little variation in the chloroplast genome between these two species (Palmer et al., 1983), it is unlikely that differences in the parental cytoplasm among the cultivars used for fusion in this and other studies account for differences in plastid sorting-out; however, interactions between the nuclear and chloroplast genomes could be involved (Sundberg and Glimelius, 1991).

The one factor that may account for selection against the $B$. oleracea cytoplasm in $\mathrm{R}_{0}$ hybrids is the treatment of this species' protoplasts with iodoacetate before fusion (Ozminkowski and
Jourdan, 1993b). There is no conclusive evidence that iodoacetate influences cytoplasmic composition in somatic hybrids, although similar results have been obtained in other somatic resynthesis of B. napus (Jourdan et al., 1989; D. Heather, personal communication). In a somatic hybridization study involving Nicotiana spp., Siderov et al. (1981) noted a lower representation of chloroplasts from the parent whose protoplasts were treated with iodoacetate before fusion and suggested that iodoacetate may reduce the competitive ability of chloroplasts in treated cells. This reduced competitive ability may be related to a general weakening of chloroplasts or to a direct reduction in the number of viable chloroplasts contributed by the treated cell. In contrast, when somatic hybrids between B. olerace $a$ and $B$. nigra were produced after iodoacetate inactivation of $B$. oleracea, chloroplasts of both parents were well represented in the $\mathrm{R}_{0}$ populations (Jourdan and Salazar, 1993). Morgan and Maliga (1987) found a bias in favor of the plastids from the IA-treated fertile $B$. napus parent; however, protoplasts of the other parent, B. napus with a male sterile Raphanus sativus cytoplasm, were irradiated, allowing the nucleus of $B$. napus nuclear genome to predominate.

Because of the heterozygosity of the species parents, the populations of hybrids reported here permitted observation of epistatic interactions between homologous genes in the two parental genomes. We found that two single-gene, dominant alleles-white flower $(W h)$ and purple anther spot $(A n)$ (Dickson and Wallace, 1986), each found in only one of the $B$. oleracea cultivar parents, retained their dominance in all type- 1 somatic hybrids. Both should be present in a simplex state (1:3 allelic ratio), one allele from each cultivar parent, if homologous genes are presumed to be present in each species. The sexual hybrids segregated for both characteristics. Flower color segregated in a 1:1 ratio, a result implying that the flower color locus of each genome exhibited typical intragenomic dominance and thus acted as homologous genes. Pubescence, a characteristic of B. rapa, was found at some stage of all somatic and sexual hybrids, a result demonstrating its dominance over glabrous vesture, a common observation among somatic hybrids between these diploid species (Jourdan et al., 1989; Taguchi and Kameya, 1986; Terada et al., 1987).

The hybrids described in this study contain a large amount of genetic variation that can be examined in subsequent generations. Among various possible characteristics to be examined are the different morphological specializations characteristics of the original parents. It may be interesting to assess the interaction of the two species' genomes in the expression of different morphologies. The production of sufficient $\mathrm{R}_{1}$ and $\mathrm{F}_{2}$ seed from these plants will permit the evaluation of segregating populations to continue assessing the outcome of such different methods of interspecific hybridization.

\section{Literature cited}

Austin, S., M.K. Ehlenfeldt, M.A. Baer, and J.P. Helgeson. 1986. Somatic hybrids produced by protoplast fusion between $S$. tuberosum and $S$. brevidens: Phenotypic variation under field conditions. Theoretical Applied Genet. 71:682-690.

Bravo, J.E. and D.A. Evans. 1985. Protoplast fusion for crop development, p. 193-220. In: J. Janick (ed.). Plant breeding reviews. AVI Publishing Co., Westport, Conn.

Dewey, D.R. 1980. Some applications and misapplications of induced polyploidy to plant breeding, p. 445-470. In: W.H. Lewis (ed.). Polyploidy: Biological relevance. Plenum Press, New York.

Dickson, M.H. and D.H. Wallace. 1986. Cabbage breeding, p. 395-432.

In: M. Bassett (ed.). Breeding vegetable crops. AVI Publishing Co., Westport, Conn.

Doyle, J.J. and E.E. Dickson. 1987. Preservation of plant sample for DNA 
restriction endonuclease analysis. Taxon 36:715-772

Evans, D.A., C.E. Flick, S.A. Kut, and S.M. Reed. 1982. Comparison of Nicotiana tabacum and Nicotiana nesophila hybrids produced by ovule culture and protoplast fusion. Theoretical Applied Genet. 62:193-198.

Glimelius, K. 1985. Sexual and somatic hybridization. Hereditas Suppl. 3:41-47.

Hadley, H.H. and S.J. Openshaw. 1980. Interspecific and intergeneric hybridization, p. 133-160. In: W.R. Fehr and H.H. Hadley (eds.). Hybridization of crop plants. Amer. Soc. Agron., Madison, Wis.

Jourdan, P.S., E.D. Earle, and M.A. Mutschler. 1989. Synthesis of male sterile, triazine-resistant Brassica napus by somatic hybridization between cytoplasmic male sterile $B$. oleracea and atrazine-resistant $B$. campestris. Theoretical Applied Genet. 78:445-455.

Jourdan, P.S. and E. Salazar. 1993. Brassica carinata resynthesized by protoplast fusion. Theoretical Applied Genet. 86:567-572.

Lester, R.N. 1989. Evolution under domestication involving disturbance of genic balance. Euphytica 44:125-132.

McGrath, J.M. and C.F. Quiros. 1991. Intersubspecies hybrids and their progeny in Brassica campestris. J. Amer. Soc. Hort. Sci. 116:349-355.

Medgyesy, P., E. Fejes, and P. Maliga. 1985. Interspecific chloroplast recombination in a Nicotiana somatic hybrid. Proc. Natl. Acad. Sci. USA 82:6960-6964.

Morgan, A. and P. Maliga. 1987. Rapid chloroplast segregation and recombination of mitochondrial DNA in Brassica cybrids. Mol. Gen. Genet. 209:240-246.

Negrutiu, I., S. Hinnisdaels, A. Mouras, B.S. Gill, G.B. Gharti-Chhetri, M.R. Davey, Y.Y. Gleba, V. Sidorov, and M. Jacobs. 1989. Somatic versus sexual hybridization: Features, facts and future. Acta Bot. Neerl. 38:253-272.

Newton, K.J. 1988. Plant mitochondrial genomes: Organization, expression, and variation. Annu. Rev. Plant Physiol. Plant Mol. Biol. 39:503-532

Ozminkowski, Jr., R.H. and P.S. Jourdan. 1993a. Expression of selfincompatibility and fertility of Brassica napus resynthesized by interspecific somatic hybridization. Euphytica 65:153-160.

Ozminkowski, Jr., R.H. and P.S. Jourdan. 1993b. Comparing the resynthesis of Brassica napus by interspecific somatic and sexual hybridization. I. Producing and identifying hybrids. J. Amer. Soc. Hort. Sci. 119:808-815.

Palmer, J.D. and C.R. Shields. 1984. Tripartite structure of the Brassica campestris mitochondrial genome. Nature 307:437-440.

Palmer, J.D., C.R. Shields, D.B. Cohen, and T.J. Orton. 1983. Chloroplast DNA evolution and the origin of amphiploid Brassica species. Theoretical Applied Genet. 65:181-189.

Peloquin S.J. and R. Ortiz. 1992. Techniques for introgressing unadapted germplasm to breeding populations, p 485-507. In: H.T. Stalker and J.P.
Murphy (eds.). Plant breeding in the 1990s. CAB International, Wallingford, U.K.

Power, J.B., K.C. Sink, S.F. Berry, S.F. Burns, and E.C. Cocking. 1978. Somatic and sexual hybrids of Petunia hybrida and Petunia parodii. J. Hered. 69:373-376.

Sabour, M., J. Simmonds, and G. Setterfield. 1986. Variation in nicotine content of cultured cell lines of Nicotiana species and their somatic and sexual hybrids. Plant Breeding 97:324-333.

Sanford J.C. 1983. Ploidy manipulations, p. 100-123. In: J.N. Moore and J. Janick (eds.). Methods in fruit breeding. Purdue Univ. Press, West Lafayette, Ind.

Schenck, H.R. and G. Röbbelen. 1982. Somatic hybrids by fusion of protoplasts from Brassica oleracea and B. campestris.Z. Pflanzenzuecht. 89:278-288.

Siderov, V.A., L. Menczel, F. Nagy, and P. Maliga. 1981. Chloroplast transfer in Nicotiana based on metabolic complementation between irradiated and iodoacetate treated protoplasts. Planta 152:341-345.

Song, K.M., T.C. Osborn, and P.H. Williams. 1990. Brassica taxonomy based on nuclear restriction fragment length polymorphisms. III. Genomic relationships in Brassica and related genera and the origin of $B$. oleracea and B. rapa (syn. campestris). Theoretical Applied Genet. 79:497-506.

Song, K.M. and T.C. Osborn. 1992. Polyphyletic origins of Brassica napus: New evidence based on organelle and nuclear RFLP analyses. Genome 35:992-1001.

Sundberg, E. and K. Glimelius. 1986. A method for the production of interspecific hybrids within Brassiceae via somatic hybridization, using resynthesis of Brassica napus as a model. Plant Sci. 43:155-162.

Sundberg, E. and K. Glimelius. 1991. Effects of parental ploidy level and genetic divergence on chromosome elimination and chloroplast segregation in somatic hybrids within Brassicaceae. Theoretical Applied Genet. 83:81-88.

Sundberg, E., M. Landgren, and K. Glimelius. 1987. Fertility and chromosome stability in Brassica napus resynthesized by protoplast fusion. Theoretical Applied Genet. 75:96-104.

Taguchi, T. and T. Kameya. 1986. Production of somatic hybrid plants between cabbage and Chinese cabbage through protoplast fusion. Jpn. J. Breeding 36:185-189.

Temple, M., C.A. Makaroff, M.A. Mutschler, and E.D. Earle. 1992. Novel mitochondrial genomes in Brassica napus somatic hybrids. Current Genet. 22:243-250.

Terada, R., Y. Yamashita, S. Nishibayashi, and K. Shimamoto. 1987. Somatic hybrids between Brassica oleracea and B. campestris: Selection by the use of iodoacetamide inactivation and regeneration ability. Theoretical Applied Genet. 73:379-384. 